\title{
Haematologic and biochemical changes in bitches with clinical and subclinical mastitis
}

\author{
Iosif VASIU ${ }^{1 *}$, Orsolya SARPATAKI ${ }^{1}$, Ioana BEDECEAN ${ }^{1}$, Raul Alexandru POP ${ }^{1}$, \\ Florinel Gheorghe BRUDAŞC $\breve{A}^{1}$ \\ ${ }^{1}$ Faculty of Veterinary Medicine, University of Agricultural Science and Veterinary Medicine Cluj- \\ Napoca, 3-5 CaleaMănăştur, Cluj-Napoca, Romania \\ * Corresponding author: iosif.vasiu@usamvcluj.ro \\ Bulletin UASVM Veterinary Medicine 73(2)/2016 \\ Print ISSN 1843-5270; Electronic ISSN 1843-5378 \\ doi:10.15835/buasvmcn-vm:11995
}

\begin{abstract}
Mastitis in bitch is in general superficially researched and evaluated. Data regarding blood tests during bitch glandular tissue inflammation is scarcely documented, therefore this paper aims to assess blood response in such cases. A total of 74 blood samples were obtained from lactating dams. These included females with Lactatio sine graviditate, with or without overt signs of mammary gland illness and with or without other signs of disease. Routine complete blood count and serum total proteins were evaluated. Complete blood count and total serum protein levels showed great flexibility, thus making it very difficult to establish and describe a clear and common haematological and biochemical pathway during mastitis inflammatory response. Clincians shoulds not relay only on blood tests whenever dealing with such pathology. Complete blood count and total serum protein levels should only be used as complementary tests, alongside other assays such as milk microbiology or cytology.
\end{abstract}

Keywords: bitch, complete blood count, mastitis, serum total protein

\section{INTRODUCTION}

In curent veterinary practice, mammary gland inflammation diagnostic is based mainly on history, clinical and microbiological examination (Traschetal., 2008). There is scarce data regarding blood changes during clinical or subclinical mastitis episodes in this species (Hasegawa et al., 1993). However, there is one experimental study (Ververidis et al., 2007). Where leukocytosis was observed immediately after mammary gland bacterial challenge. At 12 hours, shortly after inoculation, a drop in the leukocyte count was observed, then followed by an immediate increase. On the sixt day, after challenge, leukocytes were in normal range. Neutrophilia was also observed shortly after challenge, but after the $6^{\text {th }}$ day, this parameter dropped in range as well. Severe thrombocytopenia was recorded in the first hours after inoculation, followed by an increase in the $4^{\text {th }}$ day. However, there were no important changes in total serum protein levels (Ververidis et al., 2007).

The aim of this research was to evaluate whether complete blood count (CBC) and serum total proteins in lactating bitches (antepartum, postpartum and Lactatio sine graviditate), with or without overt signs of mastitis and other concurrent signs of illness, follow the same type of haematological or biochemical blood response.

\section{MATERIALS AND METHODS}

In order to evaluate haematological and biochemical changes during bitch mastitis cases, 100 lactating dams were included in a casecontrolled study, but because of owners reluctance, we were only able to obtain 74 blood samples.

Dams in this study were divided into two groups. Females with primary mastitis and females with secondary mastitis. During consult, 
females with concurrent affections were included in the second category (i.e. secondary mastitis), whereas clinically healthy females or just with clinical or subclinical mastitis, were included in the first category.

Haematology and biochemstriy assays were processed on venous blood after a thorough local disinfection with betadine (Betadine $100 \mathrm{ml}$, Egis Pharmaceuticals Ltd., Budapest, Hungary). After collection, blood samples were rushed as quickly as possible to the laboratory at the University of Agricultural Science and Veterinary Medicine ClujNapoca.

Complete blood count was determined with Abacus Junior Vet analyzer (Diatron Messtechnik, Budapest, Hungary) whilst differential blood count was counted on blood film stained with Dia-Quick Panoptic dye kit (Reag-Fix Panoptic, ReagensKft., Budapest Hungary). Biochemical results for total serum protein, were obtained with a Spectrophotometer analyzer UV-VIS Screen Master Touch (Hospitex Diagnostix, Fiorentino, Italy).

Completeblood countand serum proteinogram changes prevalence and its 95\% confidence intervals were assessed. The differences were considered significant if $p$ values were lower than 0.05. Data analysis was performed using EpiInfo 7 software (CDC, USA).

\section{RESULTS AND DISCUSSION}

In bitches with primary mastitis, $40 \%$ (4/10, CI 95\%: 6.67-65.25) of cases were recorded with Normocytic hyperchromic followed by Normocytic normochromic and Microcytic hypochromic mild anemia in 20\% (2/10, CI 95\%: 2.52-55.61) of tested samples. Normocytic normochromic moderate anemia and Normocytic hypochromic mild anemia were also present in 10\% (1/10, CI 95\%: 0.25-44.50) of the tested cases, each (Tab.1) ( $p>0.05)$. Presence of mild anemia could have been caused by the loss of blood due to inflamed mammary glands and infections (Kerr, 2002a).

Thrombocytopenia was recorded in $60 \%$ (3/5, CI 95\%: 14.66-94.73) of cases, whilst $40 \%$ (2/5, CI 95\% 5.27-85.34) were recorded with Thrombocytosis $(\mathrm{p}>0.05)$.

Mild Lecukocytosis was encountered in 4 (4/4, CI 95\%: 10.00) of the primary mastitis bitches ( $p>0.05)$.
The CBC showed that Eosinopenia was present in 21\% (4/19, CI 95\%: 6.05-45.57) of cases whilst Eosinophilia was present in only $5 \%(1 / 19$, CI 95\%: $0.13-26.03$ ) of the tested females. Monocytopenia with eosinophilia was encountered in $11 \%(2 / 19$, CI 95\%: 1.30-33.14) of the samples, followed by Monocytosis with eosinophilia and by Lymphocytosis with eosinopenia in 5\% (1/19, CI 95\%: 0.13-26.03) of the cases, each (Tab.1) ( $\mathrm{p}>0.05)$.

In $16 \% \quad(3 / 19, \quad \mathrm{CI} 95 \%: 3.38-39.58)$ of samples, CBC encountered Neutrophilia with left shift along with eosinophilia, 11\% (2/19, CI 95\%: 1.30-33.14) were with Neutrophilia with left shift along with monocytosis, showing chronic signs of disease ( $\mathrm{p}>0.05)$.

Without correlation with clinical features, 5\% (1/19, CI 95\%: 0.13-26.03) of the samples presented, Neutrophilia with a left shift with eosinopenia, lymphocytosis and eosinopenia, lymphopenia, monocytopenia and eosinophilia and also with Neutropenia with a right shift along with monocytosis, lymphocytosis and eosinophilia, each (Tab.1) ( $\mathrm{p}>0.05)$.

In 31\% (5/16, CI 95\%: 11.02-58.66) of tested samples Hyperproteinemia with hyperglobulinemia was encountered, followed by $25 \%$ (4/16, CI $95 \%$ : 7.27-52.38) of dams with Hyperglobulinemia. In 13\% (2/16, CI 95\%: 1.55-38.35) of cases presence of Hyperproteinemia with hyperalbuminemia and Hyperproteinemia with hyperalbuminemia and hyperglobulinemia was noticed. In just $6 \%$ (1/16, CI 95\%: 0.16-30.23) of cases Hyperalbuminemia followed by Hyporproteinemia and Hyperalbuminemia with hyperglobulinemia were encountered (Tab.1) ( $p>0.05)$.

Usually, elevated levels of total serum proteins, including, albumins and globulins could be caused by dehydration, chronical inflammation or chronic subacute bacterial infection (Kerr, 2002b). These hypothesis can explain the presence of high levels of these parameters in primary mastitis bitches.

In one documented bitch Mastitis gangrenosa case report, where biochemical and haematological changes were recorded, results showed presence of severe leukocytosis $(36,300 / \mu \mathrm{l})$ with marked elevated $\alpha, \beta$ and $\gamma$-globuline levels, moderate anemia, a slightly increased level of alkaline phosphatase and creatine phosphokinase with moderate hipernatremia and hypokalemia. On the day of admission, the amount of circulating leukocytes decreased temporarily to $26,000 / \mathrm{ml}$, 
Tab. 1. Hemoleucogram and biochemical results in both types of bitch mastitis

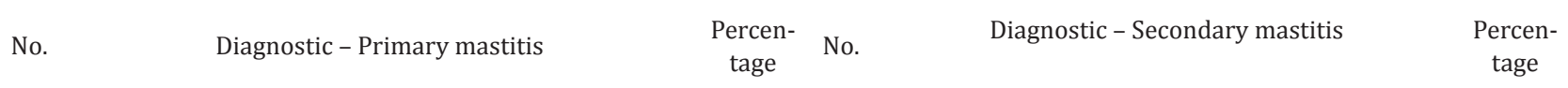

WBC

WBC

1 Mild leukocytosis

\begin{tabular}{llll} 
& $\mathbf{1}$ & Severe leukopenia & $14 \%$ \\
\hline $\mathbf{2}$ & Moderate leukocytosis & $29 \%$ \\
\cline { 2 - 4 } & $\mathbf{3}$ & Severe leukocytosis & $29 \%$ \\
\hline $\mathbf{4}$ & Mild leukocytosis & $29 \%$ \\
\hline
\end{tabular}

RBC

RBC

\begin{tabular}{|c|c|c|c|c|c|}
\hline 2 & Normocytic normochromic moderate anemia & $10 \%$ & 5 & Normocytic hypochromic moderate anemia & $14 \%$ \\
\hline 3 & Normocytic hypochromic mild anemia & $10 \%$ & 6 & Normocytic hypochromic mild anemia & $14 \%$ \\
\hline 4 & Microcytic hypochromic mild anemia & $20 \%$ & 7 & Normocytic normochromic mild anemia & $14 \%$ \\
\hline 5 & Normocytic normochromic mild anemia & $20 \%$ & 8 & Normocytic hyperchromic mild anemia & $57 \%$ \\
\hline 6 & Normocytic hyperchromic mild anemia & $40 \%$ & & & \\
\hline & PLT & & & PLT & \\
\hline 8 & Thrombocytosis & $40 \%$ & 9 & Thrombocytosis & $33 \%$ \\
\hline 9 & Thrombocytopenia & $60 \%$ & 10 & Thrombocytopenia & $67 \%$ \\
\hline
\end{tabular}

CBC

CBC

\begin{tabular}{|c|c|c|c|c|c|}
\hline 10 & Eosinophilia & $5 \%$ & 11 & Monocitopenia with eosinophilia & $6 \%$ \\
\hline 11 & Lymphocytosis with eosinopenia & $5 \%$ & 12 & $\begin{array}{l}\text { Neutrophilia with left shift with } \\
\text { lymphocytosis and eosinopenia }\end{array}$ & $6 \%$ \\
\hline 12 & Monocytosis with eosinophilia & $5 \%$ & 13 & Neutrophilia with left shift with lymphopenia & $6 \%$ \\
\hline 13 & Neutrophilia with left shift with eosinopenia & $5 \%$ & 14 & $\begin{array}{l}\text { Neutrophilia with left shift with lymphopenia, } \\
\text { monocytopenia and eosinopenia }\end{array}$ & $6 \%$ \\
\hline 14 & $\begin{array}{l}\text { Neutrophilia with left shift with } \\
\text { lymphocytosis and eosinopenia }\end{array}$ & $5 \%$ & 15 & Neutrophilia with left shift with monocytosis & $6 \%$ \\
\hline 15 & Neutrophilia with left shift with lymphopenia & $5 \%$ & 16 & Neutropenia with eosinophilia & $6 \%$ \\
\hline 16 & $\begin{array}{l}\text { Neutrophilia with left shift with } \\
\text { monocytopenia and eosinophilia }\end{array}$ & $5 \%$ & 17 & Neutrophilia with left shift & $12 \%$ \\
\hline 17 & $\begin{array}{l}\text { Neutropenia with right shift with monocytosis, } \\
\text { lymphocytosis and eosinophilia }\end{array}$ & $5 \%$ & 18 & Neutrophilia with left shift with eosinopenia & $12 \%$ \\
\hline 18 & Monocytopenia with eosinophilia & $11 \%$ & 19 & $\begin{array}{l}\text { Neutrophilia with left shift with } \\
\text { monocytosis and eosinophilia }\end{array}$ & $12 \%$ \\
\hline 19 & Neutrophilia with left shift with monocytosis & $11 \%$ & 20 & $\begin{array}{l}\text { Neutrophilia with left shift with } \\
\text { lymphopenia and eosinopenia }\end{array}$ & $29 \%$ \\
\hline 20 & Neutrophilia with left shift with eosinophilia & $16 \%$ & & & \\
\hline 21 & Eosinopenia & $21 \%$ & & & \\
\hline & Total Proteins & & & Total Proteins & \\
\hline 22 & Hyperalbuminemia & $6 \%$ & 21 & Hyperalbuminemia & $13 \%$ \\
\hline 23 & Hyperalbuminemia with hyperglobulinemia & $6 \%$ & 22 & Hyperglobulinemia & $13 \%$ \\
\hline 24 & Hyporproteinemia & $6 \%$ & 23 & Hyperproteinemia with hyperalbuminemia & $20 \%$ \\
\hline 25 & Hyperproteinemia cu hyperalbuminemia & $13 \%$ & 24 & Hyperproteinemia with hyperglobulinemia & $20 \%$ \\
\hline 26 & $\begin{array}{l}\text { Hyperproteinemia with hyperalbuminemia } \\
\text { and hyperglobulinemia }\end{array}$ & $13 \%$ & 25 & $\begin{array}{l}\text { Hyperproteinemia with hyperalbuminemia } \\
\text { and hyperglobulinemia }\end{array}$ & $33 \%$ \\
\hline 27 & Hyperglobulinemia & $25 \%$ & & & \\
\hline 28 & Hyperproteinemya with hyperglobulinemia & $31 \%$ & & & \\
\hline
\end{tabular}


but then increased to $48,600 / \mathrm{ml}$. Along with these parameters, thrombocytopenia $(179,000 / \mathrm{ml})$ with giant platelets were also recorded (Hasegawa et al., 1992).These changes are partially confirmed by our study, where mild to severe leukocytosis were recorded (Tab. 1) alongside with a left shift and increase in total protein serum levels (Tab. 1).

In bitch Mastitis acuta reports, leukocytosis with or without a left shift was encountered (Lopate, 2012). In a recent bitch Mastitis acuta case report, the authors (Vasiu et al., 2015) indicated presence of moderate anemia with leukocytosis with a left shift. Presence of eosinophilia with dehydration along with elevated liver enzymes and renal biomarkers with electrolyte imbalance, had also been reported (Lopate, 2012). Eosinophilia and eosinopenia, alongside various combinations of other types of leukocytes were, as well, recorded in our study.

In secondary mastitis cases, Normocytic hyperchromic mild anemia was diagnosed in 57\% (8/14, CI 95\%: 28.86-82.34) of cases, alongside of Normocytic hypochromic moderate anemia, Normocytic hypochromic mild anemia and Normocytic normochromic mild anemia in 14\% (2/14, CI 95\%: 1.78-42.81) of samples, each.

Thrombocytopenia was registered in $67 \%$ (4/6, CI 95\%: 22.28-95.67) of cases, whilst 33\% (2/6, CI 95\%: 4.33-77.72) of the samples were with Thrombocytosis (Tab.1).

Test results showed that in secondary mastitis cases, mild, moderate and severe Leukocytosis were encountered in 29\% (2/7, CI 95\%: 3.67 70.96) of cases, each. Severe Leukopenia was registered only in 14\% (1/7, CI 95\%: 0.36-57.87) of the tested bitches.

Complete blood count showed presence of Neutrophilia with left shift with lymphopenia and eosinopenia in 29\% (5/17, CI 95\%: 10.31-55.69) of cases, followed closely by Neutrophilia with left shift with eosinopenia and with monocytosis and eosinophilia in $12 \%(2 / 17$, CI $95 \%$ : $1.46-36.44)$ of cases, each.

Neutrophilia with left shift with monocytosis, with lymphopenia, monocytopenia and eosinopenia and lymphocytosis and eosinopenia were diagnosed in 6\% (1/17, CI 95\%: 0.15-28.69) of cases, each.

In 33\% (5/15, CI 95\%: 11.82-61.62) of evaluated samples, Hyperproteinemia with hyperal- buminemia and hyperglobulinemia were recorded, followed by Hyperproteinemia with hyperalbuminemia and Hyperproteinemia with hyperglobulinemia in 20\% (3/15, CI 95\%: 4.3348.09) of cases, each and Hyperalbuminemia and Hyperglobulinemia in 13\% of tested samples (2/15, CI 95\%: 1.66-40.46), each (Tab.1).

In secondary mastitis bitches, blood parameters should always be interpreted according to the primary underlying causes.

\section{CONCLUSION}

Haematology and biochemical assays proved to be modest and limited. The use of these tests in order to evaluate mammary gland health status in bitch should resume only as complementary assays. However, one should try to evaluate bitch mammary gland health status, alongside clinical and other paraclinical (i.e. microbiological) testing. Clinicians should avoid relaying only on these test whenever treating or diagnosing mastitis in the bitch. In cases where mastitis is secondary, one should always carefully interpret blood test and treat the dam, according to the underlying cause.

Acknowledgments. We want to thank DVM PhD student Matei Ioana Adriana for the completion of the statistical analysis and to Tressa Rebek-Nagy for reviewing and proofreading this manuscript.

\section{REFERENCES}

1. Hasegawa T, Fuji M, Fukada T, Tduji C, Fujita T, Goto Y, Shinjo T, Ogawa H (1993). Platelet abnormalities in a dog suffering from gangrenous mastitis by Staphylococcus aureus infection. J Vet Med Sci 55:169-171.

2. Kerr M (2002a). Part I: Haematology, p. 1-66. In: Kerr M (ed.). Veterinary Laboratory Medicine, Clinical Biochemistry and Haematology, Second edition, Blackwell Science. London UK.

3. Kerr M (2002b). Part II: Clinical Biochemistry, p. 67-196. In: Kerr M (ed.). Veterinary Laboratory Medicine, Clinical Biochemistry and Haematology, Second edition, Blackwell Science. London UK.

4. Lopate C (2012). Reproductive physiology of canine pregnancy and parturition and conditions of the periparturient period, p. 25-41. In: Lopate C (ed.). Management of pregnant and neonatal dogs, cats andexotic pets.WileyBlackwell.

5. Trasch K, Wehrend A (2008). Klinische, sonographische und mikrobiologische Untersuchungenbei Hündinnen mit acuter Mastitis [Clinical, ultrasonographical and 
microbiological investigations in inflamed canine mammary glands]. Tierärztl Prax 36(k):191-199.

6. Vasiu I, Spînu M, Pop Al R, Bedecean I, Sarpataky O, Brudaşcă Gh. F (2015). Mastitis acuta in a Hungarian Viszla bitch, caused by a Staphylococcus intermedius infection, [Un caz de mamită acută semnalată la o cățea de Vizsla Maghiară, produsă de o infecție cu Staphylococcus intermedius]. Rev Rom Med Vet 25(2):51-54.
7. Ververidis HN, Mavrogianni VS, Fragkou IA, Orfanou DC, Gougoulis DA, Tzivara A, Gouletsou PG, Athanasiou L, Boscos CM, Fthenakis GC (2007). Experimental Staphylococcal mastitis in bitches: Clinical, bacteriological, cytological, haematological, and pathological features. Vet Microbiol 124:95-106. 